\title{
Can(not) take my eyes off it: Attention bias for food in overweight participants
}

Citation for published version (APA):

Werthmann, J., Roefs, A., Nederkoorn, C., Mogg, K., Bradley, B. P., \& Jansen, A. (2011). Can(not) take my eyes off it: Attention bias for food in overweight participants. Health Psychology, 30(5), 561-569. https://doi.org/10.1037/a0024291

Document status and date:

Published: 01/01/2011

DOI:

10.1037/a0024291

Document Version:

Publisher's PDF, also known as Version of record

Document license:

Taverne

Please check the document version of this publication:

- A submitted manuscript is the version of the article upon submission and before peer-review. There can be important differences between the submitted version and the official published version of record.

People interested in the research are advised to contact the author for the final version of the publication, or visit the DOI to the publisher's website.

- The final author version and the galley proof are versions of the publication after peer review.

- The final published version features the final layout of the paper including the volume, issue and page numbers.

Link to publication

\footnotetext{
General rights rights.

- You may freely distribute the URL identifying the publication in the public portal. please follow below link for the End User Agreement:

www.umlib.nl/taverne-license

Take down policy

If you believe that this document breaches copyright please contact us at:

repository@maastrichtuniversity.nl

providing details and we will investigate your claim.
}

Copyright and moral rights for the publications made accessible in the public portal are retained by the authors and/or other copyright owners and it is a condition of accessing publications that users recognise and abide by the legal requirements associated with these

- Users may download and print one copy of any publication from the public portal for the purpose of private study or research.

- You may not further distribute the material or use it for any profit-making activity or commercial gain

If the publication is distributed under the terms of Article $25 \mathrm{fa}$ of the Dutch Copyright Act, indicated by the "Taverne" license above, 


\title{
Can(not) Take my Eyes off it: Attention Bias for Food in Overweight Participants
}

\author{
Jessica Werthmann, Anne Roefs, and \\ Chantal Nederkoorn \\ Maastricht University
}

\author{
Karin Mogg and Brendan P. Bradley \\ University of Southampton
}

\begin{abstract}
Anita Jansen
Maastricht University

Objective: The aim of the current study was to investigate attention biases for food cues, craving, and overeating in overweight and healthy-weight participants. Specifically, it was tested whether attention allocation processes toward high-fat foods differ between overweight and normal weight individuals and whether selective attention biases for food cues are related to craving and food intake. Method: Eye movements were recorded as a direct index of attention allocation in a sample of 22 overweight/obese and 29 healthy-weight female students during a visual probe task with food pictures. In addition, self-reported craving and actual food intake during a bogus "taste-test" were assessed. Results: Overweight participants showed an approach-avoidance pattern of attention allocation toward high-fat food. Overweight participants directed their first gaze more often toward food pictures than healthy-weight individuals, but subsequently showed reduced maintenance of attention on these pictures. For overweight participants, craving was related to initial orientation toward food. Moreover, overweight participants consumed significantly more snack food than healthy-weight participants. Conclusion: Results emphasize the importance of identifying different attention bias components in overweight individuals with regard to craving and subsequent overeating.
\end{abstract}

Keywords: overweight, attention bias, craving, overeating

On a nutrition level, obesity is caused by an imbalance of energy intake and energy expenditure. A crucial factor influencing the development of this imbalance is the "obesogenic"-food environment, which is characterized by an abundance of highly palatable food items. In such an environment, people are frequently confronted with attractive food cues, leading to a persistent temptation to indulge (Hill \& Peters, 1998; Lowe \& Levine, 2005). High-fat foods are particularly problematic because they are highly palatable and energy-dense (Polivy, Herman, \& Coelho, 2008; Schrauwen \& Westerterp, 2000). Moreover, high-fat foods are overly represented in the visual food environment because most of these foods are heavily advertised (Hoek \& Gendall, 2006). However, not everyone is equally susceptible to the constant temptations of high-fat foods in our environment (Polivy et al., 2008; Tetley, Brunstrom, \& Griffiths, 2009). Recent research (e.g., Davis et al., 2007; Giesen, Havermans, Douven, Tekelenburg, \& Jansen, 2010;

This article was published Online First July 18, 2011.

Jessica Werthmann, Anne Roefs, Chantal Nederkoorn, and Anita Jansen, Faculty of Psychology \& Neuroscience, Maastricht University, Maastricht, The Netherlands; Karin Mogg and Brendan P. Bradley, School of Psychology, University of Southampton, Southampton, United Kingdom.

We thank Irene Blanken for her help in recruiting and testing participants.

Correspondence concerning this article should be addressed to Jessica Werthmann, Faculty of Psychology and Neuroscience, P.O. Box 616, 6200 MD Maastricht, The Netherlands. E-mail: Jessica.Werthmann@ maastrichtuniversity.nl
Stice, Spoor, Ng, \& Zald, 2009) suggests that overweight and obese individuals find these foods particularly rewarding. Because high-fat foods are more rewarding, these people may selectively attend to these high-fat foods. Vice versa, a tendency to automatically notice and attend to high-fat foods may contribute to the maintenance of craving for these foods.

It has been proposed that attention biases for cues follow from attributing incentive salience to the cues (e.g., Berridge, 2009). As a consequence of a conditioning process, that is, repeated associations between food cues and a rewarding experience, the cues (e.g., the sight of palatable high-fat foods) become salient and attract attention. The food cues gain "attention grabbing powers," which enable them to capture attention, trigger or elevate craving, and elicit approach behavior toward them (Berridge, 2009; Field \& Cox, 2008; Field, Munafó, \& Franken, 2009; Franken, 2003).

Craving, in turn, plays a central role in promoting consumption and challenging control over intake (Martin, O'Neil, Tollefson, Greenway, \& White, 2008; Tiffany, 1999). It is assumed that attention biases and craving are reciprocally related, that is, attention biases for high-fat food may elicit craving, while craving can in turn trigger attention biases for high-fat food (Field \& Cox, 2008; Field et al., 2009; e.g., Ryan, 2002; Smeets, Roefs, \& Jansen, 2009). This self-perpetuating circle might, in the long run, lead to a steady preoccupation with the desired stimuli (Franken, 2003). The aim of this study is, therefore, to investigate whether the attention-grabbing potential of high-fat food cues differs between overweight and 
healthy-weight participants. It is also studied whether selective attention biases for high-fat foods are related to increased craving and food consumption.

Attention biases for motivational salient cues have already been extensively studied in the field of addiction disorders. A bias in initial orientation to addiction-related cues, which might reflect a rapid detection or vigilance mechanism, has often been observed in addiction disorders, such as nicotine and alcohol dependence (Bradley, Mogg, Wright, \& Field, 2003; Field \& Cox, 2008). Attention maintenance on relevant addiction-related stimuli (i.e., prolonged holding of attention, after initial orientation) has also been associated with craving and approach behavior toward desired drug stimuli in some addiction research, for example, young adult cigarette smokers (Field, Mogg, \& Bradley, 2004; Mogg, Field, \& Bradley, 2005). However, biases in attention maintenance can be susceptible to controlled avoidance strategies, that is, although attention may be initially directed toward reward cues (e.g., desired stimuli), some individuals may subsequently try to reduce maintained attention on them, for example, if they are actively attempting to suppress craving (Field \& Cox, 2008). Given that addiction and overeating may share common cognitive and neural mechanisms (Davis \& Carter, 2009), we expected biases in both initial orientation and attention maintenance components to be influential factors for craving and subsequent intake of high-fat foods.

Research on attention processes in participants with overweight and obesity is relatively sparse and yielded contradictory results. On a Stroop task, obese children showed greater interference in color-naming food words than did their lean counterparts (Braet \& Crombez, 2003). However, another study, using the same paradigm, reported no significant differences between obese and healthy-weight adults (Phelan et al., 2010). Moreover, a study using a letter grid with hidden food words (i.e., the imbedded food word task), also failed to find interference for food words in overweight adolescences (Soetens \& Braet, 2007).

Also, studies in which attention was directly assessed by means of eye-movement registration yielded contradictory results. A recent study (Castellanos et al., 2009), measuring eye movements during a visual probe task with food and nonfood pictures, found that obese participants, in contrast to healthyweight participants, demonstrated enhanced initial orientation toward and maintained attention on food cues. In contrast, another study that assessed eye-movements to food pictures in a passive viewing task did not find a bias in eye movement recording between obese and healthy-weight adults (Nijs, Muris, Euser, \& Franken, 2010). However, in this same study, participants also completed a visual probe task with manual response latencies as a dependent measure. In this task, overweight participants demonstrated a bias in enhanced initial orientation toward food cues but showed no bias in maintained attention (all participants, irrespective of weight, showed maintained attention on food in contrast to neutral cues). Furthermore, results from a separate attentional task assessing eventrelated potentials (ERPs, P300) suggested that some overweight participants may have used "cognitive strategies to reduce a maintained attentional bias for food stimuli" (Nijs et al., 2010, p. 243).
Whereas the findings by Castellanos et al. (2009) and Nijs et al. (2010) support the existence of the hypothesized attentional bias in initial orientation toward food cues in overweight participants, research into the biases in maintained attention, such as the study by Nijs et al. (2010), showed mixed results, possibly depending on their paradigms. In addition, the studies by Phelan et al. (2010) and Soetens and Braet (2007) yielded no differences in attentional biases for food-related words between overweight and healthy-weight participants, although Braet and Crombez (2003) found such a difference in a modified Stroop study. It is possible that the inconsistent results of earlier studies can be explained by different methodologies that were applied to study attention allocation.

Indirect measures of attention, such as the Stroop paradigm, are difficult to interpret because it is not possible to disentangle distinctive attentional processes, that is, initial attention allocation or maintained attention. The most direct way to assess attention allocation processes is to record eye movements during a visual attention paradigm. Recording of eye movements provides a direct observable, dynamic, and ecologically valid measure of visual attention processes (Mogg, Bradley, Field, \& De Houwer, 2003). Another key advantage of eye movement recording is that it is easy to accurately disentangle distinctive components of attention allocation processes, such as initial orientation and attention maintenance. Hence, we opted to employ eye-tracking during a visual probe task with food cues versus neutral cues in the current study. This direct assessment of distinctive components of attention allocation toward food might further contribute to clarify divergent results of previous studies. We further aim to extend previous findings by examining the relationships between specific attention bias components (initial orientation, attention maintenance) and craving and (over)eating. This might enable us to deduce at which stages of information processing overweight individuals differ from healthy-weight individuals when exposed to food cues and how these processes are related to eating behavior that is associated with the development of obesity.

To summarize, the current study examined attentional biases toward high-fat food in overweight and healthy-weight participants. It was hypothesized, on both theoretical and empirical grounds, that overweight participants would show a larger attentional bias in initial orientation (i.e., enhanced initial gaze direction) toward food cues as compared to healthy-weight control participants. In addition, we expected overweight and normal-weight participants to differ in their subsequent maintenance of gaze on food cues relative to nonfood cues, manifesting in both recordings of eye movements and recordings of manual response latencies during the visual probe task. The latter prediction was not directional, as overweight individuals may show either increased or reduced maintenance of attention on food cues, as discussed earlier (Castellanos et al., 2009; Nijs et al., 2010). Moreover, the hypothesis was tested that overweight participants would eat more snack food than normalweight individuals on a bogus "taste-test." We also examined whether attentional biases for food cues are related to reports of food-craving (assessed immediately before and after the attentional task) and increased food intake. 


\section{Method}

\section{Sample and Participant Selection}

The sample was comprised of 22 overweight/obese and 29 healthy-weight female students. Participants were selected for the study according to their body mass index (BMI; $\mathrm{kg} / \mathrm{m}^{2}$ ) based on their self-reported height and weight in a survey among first-year students (BMI $<25$ for healthy-weight participants and BMI $>25$ for overweight/obese participants). Exclusion criteria were serious health problems, pregnancy, and vegetarism, because food stimuli included pictures of meat. Final allocation of participants to the overweight/obese and healthy-weight groups was based on BMI measures obtained from accurate height and weight measurements taken at the end of the test session. See Table 1 for sample characteristics.

\section{Materials}

\section{Pictorial Visual Probe Paradigm}

Overview. A visual probe paradigm was employed, with concurrent recording of eye movements as a direct measure of attention allocation, and the assessment of response latencies as an indirect index of attention allocation. In the visual probe paradigm, image pairs were presented simultaneously side-by-side, followed by the presentation of a probe appearing in the location of one of the images. Participants were instructed to respond as quickly as possible by pressing a corresponding key on a button box to indicate the location of the probe. The logic of this task presumes that participants are faster in detecting probes appearing in the location of the stimulus that they attended. Conversely, it is assumed that participants are slower to respond to probes appearing in the location of the stimulus that they did not attend (MacLeod, Mathews, \& Tata, 1986).

Timing trials. Each trial started with a central fixation cross, which disappeared directly after participants fixated on it. Subsequently, the target image pair was presented for $2000 \mathrm{~ms}$. Then, the probe $(*)$, was presented until the participant responded by pressing the appropriate key on a button box.

Trial types. The visual probe paradigm included 120 trials: 80 critical trials and 40 filler trials. Critical trials consisted of 20 stimulus pairs, which were each presented four times. Filler trials consisted of 10 stimulus pairs, which were also presented four times. The position of the probe was equally distributed per stimulus type and was also equally distributed over the left and the right side of the screen. The order of trials was randomized uniquely for each participant.

Stimuli. Stimuli were naturalistic images of highly palatable food items, because food words might have weaker motivational effects (Simmons, Martin, \& Barsalou, 2005; Tiggemann \& Kemps, 2005). In critical trials, the image pair consisted of a picture of a palatable high-fat food item and a picture of a musical instrument. Filler trials consisted of picture pairs depicting two neutral nonfood pictures (office supplies and traffic objects). All image pairs were matched as closely as possible with regard to color, complexity and brightness, and size. Each picture was presented equally often on the left and on the right side of the screen.

Eye movement measurements. The visual probe paradigm was run on a Dell OptiPlex 760 Computer with a 19-in screen (resolution: $1280 \times 1024)$. Participants were seated within approximately $50-\mathrm{cm}$ distance to the screen in a dimly lit room. Eye movements were recorded by a desktop mounted EyeLink 1000 system (SR Research Ltd., Mississauga, Ontario, Canada). A 9-point calibration with subsequent validation procedure was conducted prior to the visual probe paradigm. To study attention allocation processes, participants' gaze fixations were examined. Gaze fixations were defined as any period that was not a blink or saccade and lasted at least $100 \mathrm{~ms}$ (Eyelink Dataviewer User's Manual, 2002-2008, SR Research Ltd.). Eye movements that occurred before the presentation of an image pair were excluded, because these movements could represent anticipatory fixations.

For analyses purposes, the computer screen was invisible for participants and divided into three areas of interest: the midsection, which represented the location of the fixation cross, and the left and right section, representing the locations of the picture stimuli. Only eye movements in critical trials directed either to the left or the right section of the screen were extracted for further analyses. Eye movements in filler trials and gaze fixations in the mid area were excluded from further analyses. Eye movements were extracted using Data Viewer (SR Research Ltd., Missisauga, Ontario, Canada).

Table 1

Participants' Characteristics

\begin{tabular}{|c|c|c|c|c|c|c|}
\hline \multirow[b]{2}{*}{ Variable characteristics } & \multicolumn{2}{|c|}{ Overweight/obese $(n=22)$} & \multicolumn{2}{|c|}{ Healthy weight $(n=29)$} & \multirow[b]{2}{*}{$t(49)$} & \multirow[b]{2}{*}{$p$} \\
\hline & $M(S D)$ & Range & $M(S D)$ & Range & & \\
\hline Age & $19.86(1.28)$ & $18-23$ & $19.31(1.95)$ & $18-27$ & 1.15 & .25 \\
\hline BMI & $28.03(3.74)$ & $25.09-40.04$ & $21.16(2.03)$ & $17.83-24.87$ & 8.39 & $<.001$ \\
\hline RS & $14.91(4.31)$ & $7-21$ & $8.70(4.57)$ & $1-21$ & 4.92 & $<.001$ \\
\hline DEBQ-EX & $2.83(0.49)$ & $1.80-3.70$ & $2.98(0.59)$ & $1.90-4.50$ & 0.94 & .35 \\
\hline PFS & $2.36(0.68)$ & $1.07-3.67$ & $2.20(.64)$ & $1.07-4.00$ & 0.84 & .41 \\
\hline Negative affect (PANAS) & $19.73(6.87)$ & $10-35$ & $20.41(5.80)$ & $11-31$ & 0.39 & .70 \\
\hline Positive affect (PANAS) & $35.32(5.84)$ & $24-50$ & $34.21(6.10)$ & $21-44$ & 0.66 & .52 \\
\hline
\end{tabular}

Note. $\quad$ RS $=$ Restraint Scale (Herman \& Polivy, 1980); DEBQ-EX = Dutch Eating Behavior QuestionnaireExternal Eating subscale (van Strien, et al., 1986); PFS = Power of Food Scale (Lowe, et al., 2009); PANAS = Positive and Negative Affect Scale (Watson, et al., 1988). 
Attention bias scores. Three attention bias scores were derived from the eye movement data: gaze direction bias scores, initial fixation duration bias scores, and gaze dwell time bias scores.

The gaze direction bias was based on the proportion of trials on which the first fixation was directed to a food stimulus versus a control stimulus. A fixation was defined as a first fixation on a picture if it was indeed the first fixation in that trial, but also if it was preceded by a fixation in the mid area. Following Castellanos et al. (2009), direction bias scores were calculated by computing the number of first fixations that were directed to a high-fat food picture as a proportion of all trials on which a first fixation was made to either picture. A bias score greater than $50 \%$ represents a higher proportion of first fixations directed to food stimuli, whereas a bias score less than $50 \%$ indicates a higher proportion of first fixations directed to nonfood stimuli.

The initial fixation duration bias is based on the duration of the first fixation on a critical stimulus and can be seen as a measure for early attention maintenance (e.g., Mogg et al., 2003). The initial fixation on a picture was defined as the first to occur following the onset of the picture pair. Thus, this variable represents the duration of a first fixation that is directed to one of the picture stimuli (food vs. nonfood). Initial fixation durations per image category (food or nonfood) were averaged over the relevant trials per participant. Bias scores for the initial fixation duration were computed by subtracting the mean duration of initial fixations directed to nonfood images from the mean duration of initial fixations directed to food images. Thus, a positive score is indicative of longer initial attention maintenance on food stimuli, whereas a negative score is indicative of the reverse: longer initial maintenance on nonfood stimuli.

Gaze dwell time is informative regarding the maintenance of attention on critical stimuli (e.g., Mogg et al., 2005). Overall dwell time per image category (food vs. nonfood) was summed over individual fixations across each critical trial and then averaged per image category over all trials, resulting in an average total dwell time per image category for each participant. For the gaze dwell time bias score, the mean dwell time on nonfood images was subtracted from the mean dwell time on food images. Thus, a positive score indicates that attention was maintained longer on food items than on nonfood items, whereas a negative score indicates the reverse: longer maintained attention on nonfood items.

Manual response latencies to probes. Calculations of response latency bias scores were based on the recordings of the participant's manual response latency when indicating the location of the probe. Response latencies were excluded from further analyses if they were faster than $200 \mathrm{~ms}$, slower than $2000 \mathrm{~ms}$, and then if they deviated more than $3 S D$ s from each participant's mean (e.g., Castellanos et al., 2009; Mogg, Bradley, Hyare, \& Lee, 1998). Response latency bias scores were then calculated by subtracting the mean response latency on congruent trials (that is, when the probe replaced a food image) from the mean response latency on incongruent trials (that is, when the probe appeared in the same location as the preceding nonfood image). A positive bias score indicates an attention bias toward food, whereas a negative bias score indicates an attention bias away from food.

\section{Questionnaires}

Craving and satiety. Craving was assessed by asking "How strong is your craving for food right now" on a $100-\mathrm{mm}$ visual analogue scale (VAS), ranging from "no craving at all" (0) to "extremely strong craving" (100). As adjunct to craving, satiety was also assessed by three 100-mm VAS addressing the experience of hunger and satiety. The satiety-VAS ranged from 0 , indicating an absolute absence of hunger/satiety, to 100, indicating an overwhelming presence of hunger/satiety. The VAS was originally derived as a "gold standard" method to assess pain and has recently been validated as an adequate instrument to assess appetite (see for a discussion Flint, Raben, Blundell, \& Astrup, 2000).

Body mass index. BMI was assessed at the end of the experimental session. Participants' weight (in kilograms) and height (in meters) was measured accurately, and BMI was calculated.

Taste test. Food consumption was measured by means of a bogus "taste test." Participants were instructed to rate four bowls (mean weight (in grams) $=1218.37, S D=89.52$ ) of highly palatable fat food items (chocolate, biscuits, crisps, salted peanuts) in terms of their visual attractiveness, smell, and taste. The participant was given 10 minutes to complete her ratings and was told that she was free to try as much of the offered items as she liked. Consumption was determined by weighing the bowls both before and after the "taste test" and the difference in weight from pre- to postassessment was converted into calories and used as a measure of food intake.

\section{Procedure}

The study was reviewed and approved by the local ethics committee. Participants were asked to refrain from eating two hours prior to their laboratory appointment, which was scheduled at lunch time. Previous studies indicated that hunger may obscure differences between overweight and healthy-weight participants because being hungry elevates attention focus and craving for food independent of weight status (Castellanos et al., 2009; Mogg et al., 1998; Nijs et al., 2010; Piech, Pastorino, \& Zald, 2009). Therefore, in the current study, we made sure all participants were equally satiated by providing them with a lunch before assessing eye movements during the visual probe task. Upon arrival, participants received a lunch consisting of the participant's choice of a sandwich (cheese or ham on brown bread rolls) and their choice of a yoghurt or juice drink. The lunch contained in total, approximately 400-500 calories, in accordance with the average caloric value of lunches of Dutch students (deCastro, Bellisle, Feunekes, Dalix, \& DeGraaf, 1997). After the lunch, the participant filled in the craving-VAS and the satiety-VAS (Time 1). Subsequently, she was asked to take a break for 20 minutes to ensure that satietyrelated hormones signaled satiety to the brain (e.g., Castellanos et al., 2009; Nijs et al., 2010). After the break, the participant answered the craving-VAS and the satiety-VAS again (Time 2) and then performed the visual probe paradigm. Afterward, she again completed the craving-VAS and the satiety-VAS (Time 3). Then, the participant completed another computer task that is not relevant for the current study, which lasted for 15 minutes. Subsequently, the bogus taste test was arranged. Shortly before the taste test, the participant filled in the craving-VAS and satiety-VAS 
again (Time 4) and was afterward presented with the bogus taste test. Following the taste test, the participant filled in several questionnaires about eating behavior and current affective state. These questionnaires were included to examine whether groups differed on other state and trait aspects that might be relevant for attention biases for food, such as restrained eating (Restraint Scale; Herman \& Polivy, 1980), hedonic hunger (Power of Food Scale; Lowe, et al., 2009), external eating (10 items, included in the Dutch Eating Behavior Questionnaire; van Strien, Frijters, Bergers, \& Defares, 1986), and negative versus positive affect (Watson, Clark, \& Tellegen, 1988). At the end of the experimental session, the participant's weight and height were measured. The participant was probed for suspicion and was asked to write down her thoughts on the purpose of the experiment. Finally the participant was thanked for her participation and received either one course credit or a voucher of 7.50(euro).

\section{Results}

\section{Sample Characteristics}

Overweight and healthy-weight participants differed with regard to their restrained eating style, $t(49)=4.92, p<.001$. No other significant group differences in self-reported eating behavior or current affect were observed, see Table 1 for further group details. Five additional participants were tested but were excluded from analyses because they were identified as outliers: three participants deviated in their food consumption more than $2 S D$ s from their group mean. Three participants did not move their eyes on a sufficient proportion $(<50 \%)$ of trials during the visual probe paradigm (Bradley, Mogg, \& Millar, 2000), one of whom also consumed more than $2 S D s$ above her group mean.

\section{Eye-Movements Measures}

The final sample of participants made eye movements on an average of $90.4 \%$ ( $S D=8.73$ ) of all 120 trials. Percentage of eye movements did not differ significantly between overweight and healthy-weight participants, $t(46)=0.26, p=.76$. Levene's test indicated unequal variances, $F=6.00, p=.02$, so degrees of freedom were adjusted from 49 to 46 .

\section{Attention Bias Measures}

To test our hypotheses regarding attention biases, independent samples $t$ tests were conducted with weight status $(\mathrm{BMI}>25$ : overweight; $\mathrm{BMI}<25$ : healthy-weight) as the between group factor and attention bias scores as the dependent variables. Alpha level was set to .05, two-tailed, unless otherwise specified. For the mean attention bias scores, see Table 2 and Figure 1.

Gaze direction bias. In line with our hypothesis, it was found that overweight participants directed their first fixation more often to food images than to nonfood images as compared to healthyweight participants, $t(49)=1.83, p<.05$, one-tailed, $d=.52$.

Initial fixation duration bias. Overweight participants had significantly shorter initial gaze fixation durations when they fixated their first gaze on food images than when they fixated their first gaze on nonfood images as compared to healthy-weight participants, $t(49)=2.17, p<.05, d=.62$.

Gaze dwell time bias. This bias score did not differ significantly between the overweight and healthy-weight groups, $t(49)=0.25, p=.80$.

Probe manual response latency bias. This bias score did not differ significantly between the overweight and healthy-weight groups, $t(49)=1.35, p=.18$.

\section{Attention Bias, Craving, and Overeating}

Food consumption. In line with our hypothesis, overweight participants ate significantly more calories of snack food during the bogus taste test than did healthy-weight participants, $t(38)=$ $1.87, p<.05$, one-tailed, $d=.61$. Levene's test indicated unequal variances, $F=6.45, p=.01$, so degrees of freedom were adjusted from 49 to 38 .

Craving. Self-reported craving did not differ between groups at any time point, all $t(49)<1.20$, all $p s>.24$. Similarly, there were no significant differences observed on satiety levels between groups at any time point, all $t(49)<1.23$, all $p \mathrm{~s}>.22$.

Table 2

Mean Attention Bias Scores and Mean Food Intake (in Calories) for Overweight/Obese and Healthy Weight Participants, Respectively

\begin{tabular}{|c|c|c|c|c|}
\hline \multirow[b]{2}{*}{ Variable } & \multicolumn{2}{|c|}{$\begin{array}{l}\text { Overweight/obese } \\
\quad(n=22)\end{array}$} & \multicolumn{2}{|c|}{$\begin{array}{l}\text { Healthy weight } \\
\quad(n=29)\end{array}$} \\
\hline & $M$ & $S D$ & $M$ & $S D$ \\
\hline \multicolumn{5}{|l|}{ Attention bias scores } \\
\hline Gaze direction bias (\%) & 53.70 & 5.00 & 51.33 & 4.20 \\
\hline Initial fixation duration bias (ms) & -15.59 & 51.91 & 14.29 & 46.03 \\
\hline Gaze dwell time bias (ms) & -2.33 & 152.13 & 8.09 & 139.35 \\
\hline Response latency bias (ms) & -7.22 & 20.67 & 0.76 & 21.18 \\
\hline \multicolumn{5}{|l|}{ Food intake } \\
\hline Calories consumed & 165.92 & 97.15 & 119.95 & 71.63 \\
\hline
\end{tabular}

Note. Gaze direction bias $=\mathrm{N}$ of first fixations on high-fat food stimuli/ $(\mathrm{N}$ of first fixations on high-fat food stimuli $+\mathrm{N}$ of first fixations on nonfood stimuli) $* 100$. Initial fixation duration bias = mean initial fixation duration on high-fat food stimuli - mean initial fixation duration on nonfood stimuli. Gaze dwell time bias $=$ mean total dwell time on high-fat food stimuli - mean total dwell time on nonfood stimuli. 

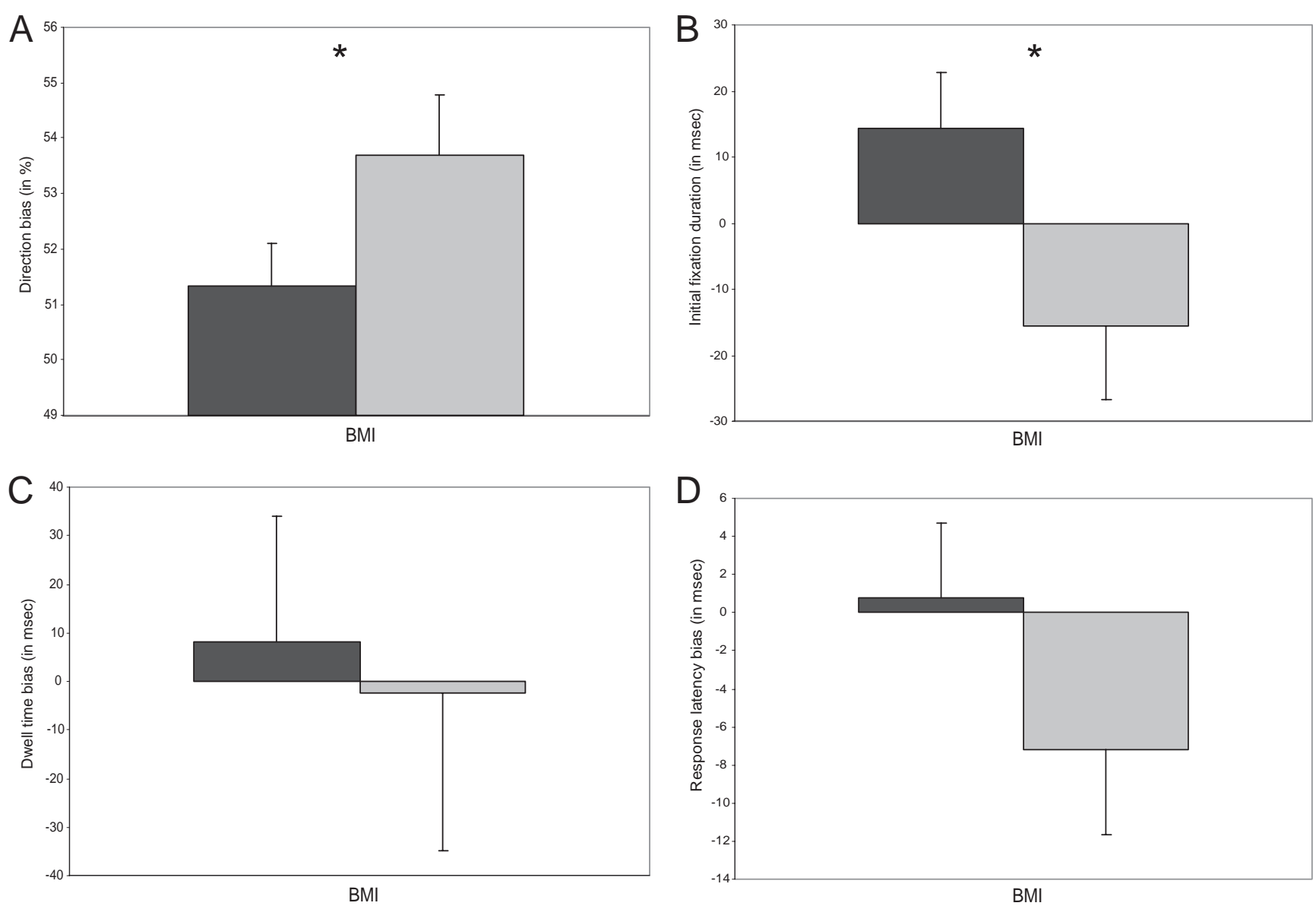

Figure 1. Graph of the mean attention bias scores (with standard errors) per condition (healthy-weight/ overweight) and bias type. Quadrant A presents mean gaze direction bias scores per group. Quadrant B depicts mean initial fixation duration bias scores per group. Quadrant $C$ shows mean gaze dwell time bias scores per group. Quadrant D displays mean manual response latency bias scores per group. $\square$ Healthy-weight; $\square$ Overweight/Obese. ${ }^{*} p<.05$.

Correlation analyses. Bivariate correlations among the two measures of attention biases that revealed significant differences between groups (i.e., gaze direction bias and initial fixation duration bias), and self-reported craving shortly prior (Time 2) and directly after (Time 3 ) the visual probe task, and food intake were conducted. Correlations were computed for the group as a whole and for the overweight and healthy-weight groups separately. The results of these correlation analyses were corrected for multiple testing by adjusting the $p$ value. For the correlational analyses with craving, the $p$ values were multiplied by 4 ( 2 attentional bias scores $* 2$ measures of craving), and for the analyses with food intake, the $p$ values were multiplied by 2 ( 2 attentional bias scores). A positive relationship of self-reported craving prior to the visual probe task (Time 2) and gaze direction bias scores was found uniquely for the overweight group, $r(22)=.55$, corrected $p=.032$. No other significant correlations of attention biases and craving or food consumption were found.

\section{Discussion}

The aim of this study was to examine whether specific attention allocation processes toward high-fat food distinguish overweight from healthy-weight participants, and how attentional biases for high-fat food relate to craving and subsequent food consumption across these groups. Our key findings were that, in comparison with healthy-weight individuals, overweight participants showed (a) more frequent initial orientations toward high- fat food, but (b) diminished initial fixation durations (i.e., after initial orienting, they showed reduced holding of attention on food cues). In addition, (c) overweight individuals consumed more snack food on a subsequent taste test than did healthy-weight participants and, among overweight individuals, (d) craving was positively associated with the initial orientation direction bias toward high-fat food.

As compared to healthy-weight participants, overweight participants directed their initial gaze more often toward high-fat food pictures during the visual probe task. This is in line with our hypothesis and consistent with findings of previous studies observing a heightened vigilance of food cues in overweight and obese participants (Castellanos et al., 2009; Nijs et al., 2010). Contrary to this bias in initial orientation toward food cues, overweight participants showed significantly reduced initial fixation durations for food, which suggests a relatively rapid and immediate attentional shift away from food stimuli. This finding seems 
unexpected in relation to previous research that reported increased maintained attention (reflected by prolonged gaze dwell time) for food cues in obese participants (Castellanos et al., 2009). Instead, the present finding seems more compatible with other research evidence (using ERP P300), which suggested that some overweight individuals have reduced maintained attention on food cues (Nijs et al., 2010).

On the gaze dwell time bias (which was assessed over the entire trial duration), no differences between groups were found. It is possible that the absence of an attention maintenance bias in overweight participants reflects a strategy to avoid focusing for a longer time at food. While the current study, testing mainly overweight participants, failed to find this gaze dwell time bias (which is similar to nonsignificant gaze dwell time results in Nijs et al., 2010), others have reported increased gaze dwell time bias for food cues in heavily obese participants (Castellanos et al., 2009). Thus, another explanation for the absence of this bias is that the attention maintenance bias for food might be specific for obese individuals.

Analyses of manual response latencies did not reveal differences between overweight and healthy-weight participants regarding their reactions to congruent versus incongruent trials. The absence of a significant effect might be attributable to the relatively long stimulus duration of $2000 \mathrm{~ms}$. In the traditional visual-probe task, such long stimulus duration are used to examine attention maintenance. Findings of eye-movement recordings, however, showed that group difference emerged only at an early stage of attention allocation, namely in the initial fixation phase. The nonsignificant difference in response latencies suggest that groups did not differ in their attention allocation at a later phase of recordings. This result highlights the advantage of recording eye movements in addition to recording manual response latencies, because the latter are an indirect and relatively limited measure of attention processes (Field et al., 2009), as, in the present study, they only assessed attention bias at one specific point in time (i.e., $2000 \mathrm{~ms}$ after picture onset).

Overall, the observed pattern of attention allocation in the present study resembles an approach-avoidance reaction toward food in overweight participants. The approach component presumably arises because food cues are more salient for overweight participants than for healthy-weight participants, possibly reflecting a greater motivational value of these foods (Berridge, 1996). The avoidance component might reflect negative associations with the consequences of indulgence, such as gaining further weight, feelings of guilt and shame, unhealthy nutrition properties, and the stigma of being overweight (Macht, Gerer, \& Ellgring, 2003; Puhl \& Heuer, 2009; Thomas, Hyde, Karunaratne, Herbert, \& Komesaroff, 2008).

Theoretical accounts derived from addiction research suggest that an approach-avoidance conflict toward desired stimuli may result when consumption of desired stimuli is associated with positive reinforcement while simultaneously associations with negative consequences of consumption are activated (e.g., Breiner, Stritzke, \& Lang, 1999). The observed pattern of eye-movements initially toward food, and then subsequently away from food, might reflect similar evaluation mechanisms in overweight participants. Likewise, a study on chocolate craving observed a comparable approach-avoidance pattern in chocolate cravers, suggesting that this ambivalence may occur in response to "forbidden" but desired stimuli (Cartwright \& Stritzke, 2008).
Further, these results might suggest that attention direction on desired stimuli represents the automatic attraction of these cues, whereas attentional avoidance of desired stimuli might be a voluntary strategy to resist consumption. In line with this view, a similar attention allocation process has been observed in studies with alcohol-dependent patients. Several studies showed that alcoholics who are trying to remain abstinent, for example clinic attendants, showed an approach-avoidance pattern toward alcohol stimuli, whereas social (heavy) drinkers and alcohol dependent patients with a short duration of abstinence did not (Noël et al., 2006; Townshend \& Duka, 2007; Vollstädt-Klein, Loeber, von der Goltz, Mann, \& Kiefer, 2009).

Further support for this idea comes from research on attention allocation to food in restrained eaters (individuals with chronic weight concerns who have the intention to lose weight), showing a similar pattern of approach and avoidance when confronted with food images (Hollitt, Kemps, Tiggemann, Smeets, \& Mills, 2010; Veenstra, de Jong, Koster, \& Roefs, 2010). Similarly, Nijs et al. (2010) suggested that obese participants in their study might have used cognitive techniques to reduce attention allocation on food stimuli, possibly in an attempt to prevent excessive food intake. Thus, there seem to be two feasible explanations accounting for the observed approach-avoidance pattern of attention allocation: overweight participants might have more ambivalent feelings toward high-fat food than normal weight participants and this becomes apparent in their visual attention patterns. Or, overweight participants might try to avoid high-fat food stimuli in order to prevent feeling tempted by the sight of it.

A further aim of this study was to investigate the relation between attentional biases and craving. Results yielded uniquely for overweight participants that self-reported craving prior to the visual probe task was associated with a stronger bias in initial orientation toward foods. This finding stresses specifically for overweight participants the relevance of craving with regard to initial attention allocation. It highlights the dilemma of overweight people when exposed to highly palatable food cues: if craving enhances attentional biases for these food cues, this may increase the likelihood of their noticing any minor cues relating to highly palatable food in their environment (potentially triggering foodrelated intrusive thoughts and preoccupations), which might in turn further increase the temptation to indulge in these foods (though this latter consequence was not supported by the current data), and attentional avoidance of food stimuli might serve as a strategy to escape this vicious circle.

The results of the current study may provide further insight into the relation between attentional biases and food consumption: overweight participants ate significantly more snack food than did healthy-weight participants during the bogus taste test. Note that this difference cannot be explained by differences in hunger or craving. This result might suggest that despite a quick attention shift away from food, overweight participants found it hard to control their eating behavior when exposed to palatable high fat foods. This finding might further suggest that the effect of attentional avoidance might be short lived. Apparently, quickly looking away from food did not help overweight participants to resist palatable food that was offered to them 15 minutes later (during the bogus taste test).

The results of this study should be interpreted under the consideration of some limitations: the causal interplay of our main 
variables cannot be deduced based on our results. Future research should examine the causal relations of craving, attention allocation processes, and eating behavior experimentally, for example by inducing craving or attention biases. Considering that our sample consisted of young female students, it is questionable whether the results can be generalized to the wider population. It is to note that we conducted this study within a relatively small sample; nevertheless, we were able to show significant differences between groups in initial attentional biases. Moreover, our sample, which consisted of mainly mildly overweight individuals, did not show the expected attention maintenance component in gaze dwell time (i.e., increased dwell time on food cues assessed across the whole duration of stimulus presentation) that was earlier found in heavy obese participants (Castellanos et al., 2009). Future studies should further investigate the possible differences in attention allocation processes between overweight and heavy obese participants. This difference between overweight and heavy obese participants might indicate that specific attention components might be involved at different stages in the process of developing obesity. Future research may further explore this development, for example by testing whether specific attention biases are related to weight changes in the future.

With these specifications in mind, we draw the following conclusions. The results emphasize the environmental influence on information processing of food cues, that is attention allocation, and subsequent food intake, at least for overweight individuals. Extensive advertising and aggressive marketing of high-fat food products, designed to catch attention, might have a differential impact on healthy-weight versus overweight individuals. The results of the current study point out that it might be problematic for overweight individuals to resist these tempting offers, because they might be more likely to spot high-fat foods, particularly while craving, and might then have difficulties to refrain from eating high-fat foods, contributing to further weight gain. A general assumption in obesity research is that the so-called "toxic" food environment plays a crucial role in the dramatic increase of overweight and obesity rates in the western world. Individuals who are selectively paying attention to high fat food cues in this environment might be at increased risk to develop obesity. However, few studies have directly tested whether attentional biases for the high fat food items indeed play a role in this development. To our best knowledge, the current study is the first to identify, in overweight/ obese individuals, a distinctive pattern of cognitive bias in specific components of attention, which were directly assessed through eye movement recording, that is, enhanced initial orientation to palatable food cues, which was positively related to food-craving, but which was rapidly and immediately followed by reduced attentional maintenance on those food cues.

In summary, the current study provides evidence for individual differences in attention biases for high-fat foods in overweight versus healthy-weight participants. Overweight participants showed an approach-avoidance pattern of attention allocation toward high-fat food: overweight participants directed their first gaze more often toward the food picture but did not maintain their initial gaze on this picture. Furthermore, overweight individuals consumed more food on a subsequent taste test, and correlational data indicated a unique association between craving and attention bias in initial orientation to food cues for overweight participants. These results highlight the importance of clarifying the role of attentional mechanisms contributing to overeating in overweight individuals.

\section{References}

Berridge, K. C. (1996). Food reward: Brain substrates of wanting and liking. Neuroscience \& Biobehavioral Reviews, 20, 1-25. doi:10.1016/ 0149-7634(95)00033-B

Berridge, K. C. (2009). 'Liking' and 'wanting' food rewards: Brain substrates and roles in eating disorders. Physiology \& Behavior, 97(5), 537-550. doi:10.1016/j.physbeh.2009.02.044

Bradley, B. P., Mogg, K., \& Millar, N. H. (2000). Covert and overt orienting of attention to emotional faces in anxiety. Cognition \& Emotion, 14(6), 789-808. doi:10.1080/02699930050156636

Bradley, B. P., Mogg, K., Wright, T., \& Field, M. (2003). Attentional bias in drug dependence: Vigilance for cigarette-related cues in smokers. Psychology of Addictive Behaviors, 17(1), 66-72. doi:10.1037/0893164X.17.1.66

Braet, C., \& Crombez, G. (2003). Cognitive interference due to food cues in childhood obesity. Journal of Clinical Child and Adolescent Psychology, 32(1), 32-39.

Breiner, M. J., Stritzke, W. G. K., \& Lang, A. R. (1999). Approaching avoidance: A step essential to the understanding of craving. Alcohol Research \& Health, 23(3), 197-206. doi:10.1016/j.appet.2008.10.007

Cartwright, F., \& Stritzke, W. G. K. (2008). A multidimensional ambivalence model of chocolate craving: Construct validity and associations with chocolate consumption and disordered eating. Eating Behaviors, 9(1), 1-12. doi:10.1016/j.eatbeh.2007.01.006

Castellanos, E. H., Charboneau, E., Dietrich, M. S., Park, S., Bradley, B. P., Mogg, K., \& Cowan, R. L. (2009). Obese adults have visual attention bias for food cue images: Evidence for altered reward system function. International Journal of Obesity, 33(9), 1063-1073. doi: 10.1038/ijo.2009.138

Davis, C., \& Carter, J. C. (2009). Compulsive overeating as an addiction disorder. A review of theory and evidence. Appetite, 53(1), 1-8. doi: 10.1016/j.appet.2009.05.018

Davis, C., Patte, K., Levitan, R., Reid, C., Tweed, S., \& Curtis, C. (2007). From motivation to behaviour: A model of reward sensitivity, overeating, and food preferences in the risk profile for obesity. Appetite, 48(1), 12-19. doi:10.1016/j.appet.2006.05.016

deCastro, J. M., Bellisle, F., Feunekes, G. I. J., Dalix, A. M., \& DeGraaf, C. (1997). Culture and meal patterns: A comparison of the food intake of free-living American, Dutch, and French students. Nutrition Research, 17(5), 807-829.

Eyelink 1000 [Apparatus and software] (2010). Mississauga, ON, Canada: SR Research.

EyeLink Data Viewer User's Manual (Document Version 1.11.1). (2011). Mississauga, ON, Canada: SR Research Ltd.

Field, M., \& Cox, W. M. (2008). Attentional bias in addictive behaviors: A review of its development, causes, and consequences. Drug and Alcohol Dependence, 97(1-2), 1-20. doi:10.1016/j.drugalcdep.2008.03.030

Field, M., Mogg, K., \& Bradley, B. P. (2004). Eye movements to smokingrelated cues: Effects of nicotine deprivation. Psychopharmacology, 173(1/2), 116-123. doi:10.1007/s00213-003-1689-2

Field, M., Munafó, M. R., \& Franken, I. H. A. (2009). A meta-analytic investigation of the relationship between attentional bias and subjective craving in substance abuse. Psychological Bulletin, 135(4), 589-607. doi: $10.1037 / \mathrm{a} 0015843$

Flint, A., Raben, A., Blundell, J. E., \& Astrup, A. (2000). Reproducibility, power and validity of visual analogue scares in assessment of appetite sensations in single test meal studies. International Journal of Obesity, 24(1), 38-48.

Franken, I. H. A. (2003). Drug craving and addiction: Integrating psychological and neuropsychopharmacological approaches. Progress in 
Neuro-Psychopharmacology \& Biological Psychiatry, 27(4), 563-579. doi:10.1016/S0278-5846(03)00081-2

Giesen, J. C. A. H., Havermans, R. C., Douven, A., Tekelenburg, M., \& Jansen, A. (2010). Will work for snack food: The association of BMI and snack reinforcement. Obesity, 18, 966-970. doi:10.1038/oby.2010.20

Herman, C. P., \& Polivy, J. (1980). Restrained Eating. In A. J. Stunkard (Ed.), Obesity (pp. 209-224). Philadelphia: Saunders.

Hill, J. O., \& Peters, J. C. (1998). Environmental contributions to the obesity epidemic. Science, 280(5368), 1371-1374. doi:10.1126/ science.280.5368.1371

Hoek, J., \& Gendall, P. (2006). Advertising and obesity: A behavioral perspective. Journal of Health Communication, 11(4), 409-423. doi: 10.1080/10810730600671888

Hollitt, S., Kemps, E., Tiggemann, M., Smeets, E., \& Mills, J. S. (2010). Components of attentional bias for food cues among restrained eaters. Appetite, 54(2), 309-313. doi:10.1016/j.appet.2009.12.005

Lowe, M. R., Butryn, M. L., Didie, E. R., Annunziato, R. A., Thomas, J. G., Crerand, C. E., . . Halford, J. (2009). The Power of Food Scale. A new measure of the psychological influence of the food environment. Appetite, 53(1), 114-118. doi:10.1016/j.appet.2009.05.016

Lowe, M. R., \& Levine, A. S. (2005). Eating Motives and the Controversy over Dieting: Eating Less Than Needed versus Less Than Wanted. Obesity Research, 13(5), 797-806. doi:10.1038/oby.2005.90

Macht, M., Gerer, J., \& Ellgring, H. (2003). Emotions in overweight and normal-weight women immediately after eating foods differing in energy. Physiology \& Behavior, 80(2-3), 367-374. doi:10.1016/j.physbeh .2003 .08 .012

MacLeod, C., Mathews, A., \& Tata, P. (1986). Attentional bias in emotional disorders. Journal of Abnormal Psychology, 95(1), 15-20.

Martin, C. K., O’Neil, P. M., Tollefson, G., Greenway, F. L., \& White, M. A. (2008). The association between food cravings and consumption of specific foods in a laboratory taste test. Appetite, 51(2), 324-326. doi:10.1016/j.appet.2008.03.002

Mogg, K., Bradley, B. P., Field, M., \& De Houwer, J. (2003). Eye movements to smoking-related pictures in smokers: Relationship between attentional biases and implicit and explicit measures of stimulus valence. Addiction, 98(6), 825-836. doi:10.1046/j.13600443.2003.00392.x

Mogg, K., Bradley, B. P., Hyare, H., \& Lee, S. (1998). Selective attention to food-related stimuli in hunger: Are attentional biases specific to emotional and psychopathological states, or are they also found in normal drive states? Behaviour Research and Therapy, 36(2), 227-237. doi:10.1016/S0005-7967(97)00062-4

Mogg, K., Field, M., \& Bradley, B. P. (2005). Attentional and approach biases for smoking cues in smokers: An investigation of competing theoretical views of addiction. Psychopharmacology, 180(2), 333-341. doi: $10.1007 / \mathrm{s} 00213-005-2158-\mathrm{x}$

Nijs, I. M. T., Muris, P., Euser, A. S., \& Franken, I. H. A. (2010). Differences in attention to food and food intake between overweight/ obese and normal-weight females under conditions of hunger and satiety. Appetite, 54(2), 243-254. doi:10.1016/j.appet.2009.11.004

Noël, X., Colmant, M., Van Der Linden, M., Bechara, A., Bullens, Q., Hanak, C., \& Verbanck, P. (2006). Time course of attention for alcohol cues in abstinent alcoholic patients: The role of initial orienting. Alcoholism: Clinical and Experimental Research, 30(11), 1871-1877. doi: 10.1111/j.1530-0277.2006.00224.x

Phelan, S., Hassenstab, J., McCaffery, J. M., Sweet, L., Raynor, H. A., Cohen, R. A., \& Wing, R. R. (2010). Cognitive Interference From Food Cues in Weight Loss Maintainers, Normal Weight, and Obese Individuals. Advance online publication. Obesity, 19, 69-73. doi:10.1038/ oby. 2010.138
Piech, R. M., Pastorino, M. T., \& Zald, D. H. (2009). All I saw was the cake. Hunger effects on attentional capture by visual food cues. Appetite, 54(3), 579-582. doi:10.1016/j.appet.2009.11.003

Polivy, J., Herman, C. P., \& Coelho, J. S. (2008). Caloric restriction in the presence of attractive food cues: External cues, eating, and weight. Physiology \& Behavior, 94(5), 729-733. doi:10.1016/j.physbeh.2008.04.010

Puhl, R. M., \& Heuer, C. A. (2009). The stigma of obesity: A review and update. Obesity, 17(5), 941-964. doi:10.1038/oby.2008.636

Ryan, F. (2002). Detected, selected, and sometimes neglected: Cognitive processing of cues in addiction. Experimental and Clinical Psychopharmacology, 10(2), 67-76. doi:10.1037//1064-1297.10.2.67

Schrauwen, P., \& Westerterp, K. R. (2000). The role of high-fat diets and physical activity in the regulation of body weight. British Journal of Nutrition, 84, 417-427. doi:10.1017/S0007114500001720

Simmons, W. K., Martin, A., \& Barsalou, L. W. (2005). Pictures of Appetizing Foods Activate Gustatory Cortices for Taste and Reward. Cerebral Cortex, 15(10), 1602-1608. doi:10.1093/cercor/bhi038

Smeets, E., Roefs, A., \& Jansen, A. (2009). Experimentally induced chocolate craving leads to an attentional bias in increased distraction but not in speeded detection. Appetite, 53(3), 370-375. doi:10.1016/ j.appet.2009.07.020

Soetens, B., \& Braet, C. (2007). Information processing of food cues in overweight and normal weight adolescents. British Journal of Health Psychology, 12, 285-304. doi:10.1348/135910706X107604

Stice, E., Spoor, S., Ng, J., \& Zald, D. H. (2009). Relation of obesity to consummatory and anticipatory food reward. Physiology \& Behavior, 97(5), 551-560. doi:10.1016/j.physbeh.2009.03.020

Tetley, A., Brunstrom, J., \& Griffiths, P. (2009). Individual differences in food-cue reactivity. The role of BMI and everyday portion-size selections. Appetite, 52, 614-620. doi:10.1016/j.appet.2009.02.005

Thomas, S. L., Hyde, J., Karunaratne, A., Herbert, D., \& Komesaroff, P. A. (2008). Being 'fat' in today's world: A qualitative study of the lived experiences of people with obesity in Australia. Health Expectations: An International Journal of Public Participation in Health Care \& Health Policy, 11(4), 321-330. doi:10.1111/j.1369-7625.2008.00490.x

Tiffany, S. T. (1999). Cognitive concepts of craving. Alcohol Research \& Health, 23(3), 215-224.

Tiggemann, M., \& Kemps, E. (2005). The phenomenology of food cravings: The role of mental imagery. Appetite, 45(3), 305-313.

Townshend, J. M., \& Duka, T. (2007). Avoidance of alcohol-related stimuli in alcohol-dependent inpatients. Alcoholism: Clinical and Experimental Research, 31(8), 1349-1357. doi:10.1111/j.15300277.2007.00429.x

van Strien, T., Frijters, J. E. R., Bergers, G. P. A., \& Defares, P. B. (1986). The Dutch Eating Behavior Questionnaire (DEBQ) for assessment of restrained emotional, and external eating behavior. International Journal of Eating Disorders, 5(2), 295-315. doi:10.1002/1098-108X(198602)5:2<295::AIDEAT2260050209>3.0.CO;2-T

Veenstra, E. M., de Jong, P. J., Koster, E. H. W., \& Roefs, A. (2010), Attentional avoidance of high-fat food in unsuccessful dieters. Journal of Behavior Therapy and Experimental Psychiatry, 41(3), 282-288. doi:10.1016/j.jbtep.2010.02.006

Vollstädt-Klein, S., Loeber, S., von der Goltz, C., Mann, K., \& Kiefer, F. (2009). Avoidance of alcohol-related stimuli increases during the early stage of abstinence in alcohol-dependent patients. Alcohol and Alcoholism, 44(5), 458-463. doi:10.1093/alcalc/agp056

Watson, D., Clark, L. A., \& Tellegen, A. (1988). Development and validation of brief measures of positive and negative affect: The PANAS scales. Journal of Personality and Social Psychology, 54(6), 1063-1070. doi:10.1037/0022-3514.54.6.1063 